\title{
Construct validity, test-retest reliability, and the ability to detect change of the Canadian Occupational Performance Measure in a spinal cord injury population
}

\author{
Anna Berardi ${ }^{1} \cdot$ Giovanni Galeoto $\mathbb{D}^{2} \cdot$ Domenico Guarino $^{3} \cdot$ Maria Auxiliadora Marquez ${ }^{4} \cdot$ Rita $^{\text {De Santis }}{ }^{5}$. \\ Donatella Valente $^{6} \cdot$ Giulia Caporale $^{1} \cdot$ Marco Tofani $^{7}{ }^{7}$
}

Received: 1 February 2019 / Revised: 3 May 2019 / Accepted: 3 May 2019

(c) International Spinal Cord Society 2019

\begin{abstract}
Study design Cross-sectional study.

Objectives To examine the construct validity and the ability to detect change, of the Italian version of the Canadian Occupational Performance Measure (COPM) in a spinal cord injury (SCI) population.

Settings Rehabilitation service of the Paraplegic Center of Ostia, Italy.

Methods Thirty-nine spinal cord injury participants were recruited. The clinimetric properties of the measure were assessed following international guidelines. Cronbach's alpha and the intraclass correlation coefficient were assessed for internal consistency and test-retest reliability, respectively. Construct validity was evaluated, by calculating correlation between COPM and the Spinal Cord Independence Measure (SCIM) through Pearson's correlation coefficient and Spearman's Rho. The ability to detect change was evaluated on the overall sample.

Results The COPM was shown to be reliable in a spinal cord injury sample with positive and statistically significant results for Cronbach's alpha (0.89) and ICC (0.99 for the performance subtest and 0.98 for the satisfaction subtest). Correlation coefficients did not show a correlation between the COPM total score and the SCIM. The COPM scores improved significantly during in-patient rehabilitation, moreover the mean change between the start of treatment and the end of the therapy as evaluated with the Wilcoxon signed-rank test was -4.25 points for the performance score and -2.96 points for the satisfaction score.

Conclusions This study showed that the COPM is a reliable tool for assessing SCI clients' perceived performance of daily activities and their satisfaction with their performance.
\end{abstract}

Giovanni Galeoto

giovanni.galeoto@uniroma1.it

1 Sapienza University of Rome, Rome, Italy

2 Department of Public Health and Infectious Disease, Sapienza University of Rome, Rome, Italy

3 Montecatone Rehabilitation Institute S.P.A, Imola, Italy

4 Paraplegic Center Ostia, Ostia, Italy

5 Department of Anatomical, Histological, Forensic and Orthopedic Sciences, Sapienza University of Rome, Rome, Italy

6 Department of Human Neurosciences, Sapienza University of Rome, Rome, Italy

7 Neurorehabilitation Unit, Department of Neurosciences and Neurorehabilitation Bambino Gesù Children's Hospital, Rome, Italy

\section{Introduction}

Spinal cord injury (SCI) is an event that results not only in disorders to normal sensory, motor, or autonomic function but also affects an individual's physical, psychological, and social well-being [1]. The primary area of focus in rehabilitation includes preventing secondary complications following injury, other goals comprise improving the individual's independence in the activities of daily living, helping the individual accept the new lifestyle, facilitating community reintegration, and improving quality of life. In the present article, we refer to quality of life (QOL) as healthrelated quality of life (HR-QOL) [2,3], which is a subjective and multi-dimensional concept that includes domains related to occupational functioning (physical, mental, social dimensions, spiritual dimensions etc.) [4]. Physical functioning (one of the dimensions of HR-QOL) [5, 6] is defined as the 
ability to perform different physical activities, ranging from simple ones to more complex ones that require higher rates of endurance, strength, or mobility [7].

Functioning and HR-QOL correspond to the concept of occupational performance, which is defined as the ability to choose, organize, and satisfactorily perform meaningful activities and the tasks of everyday life, which are specific to the individual. Occupation refers to everything that people do, including self-care, leisure, and productivity [8]. The importance that people attribute to specific occupational activities may differ. Researchers have observed that, in various clinical populations and settings, when the clients' preferences are integrated into evaluations and treatments, benefits in terms of motivation, participation, and functional recovery occur [9-11]. To determine and prioritize client-specific occupational problems and to assess improvement in these problems, Law et al., in 2005, developed the Canadian Occupational Performance Measure (COPM) [12]. The COPM is an individualized, clientcentered instrument designed to measure an individual's self-perception of physical functioning and satisfaction in the activities identified as important by the client. The therapist starts the COPM semi-structured interview by asking the client to identify important daily activities that he or she wants to do, needs to do, or is expected to do but is unable to perform. Areas of everyday living explored during the interview include self-care, productivity, and leisure time. The COPM can be utilized for many different population categories, regardless of diagnosis, as long as the respondents are able to reflect on and report the activities they do every day. Recently, it has been used as an outcome measure on several studies on SCI rehabilitation [13-17]. It is currently used in over 40 countries and has been translated into more than 35 languages. Furthermore, there exists a consensus on the practicability of the COPM for different populations [18-27], as an instrument for establishing target outcomes and planning multidisciplinary interventions by identifying problems in daily activities [28-33]. The evidence from past analyses offers useful and significant insights into its clinical applications; even so, these results cannot be generalized or directly translated to resolve the difficulties encountered when administering formal goal setting actions with SCI individuals [27, 34]. The COPM is a supplemental instrument as designated by the National Institute of Neurological Disorders and Stroke in an overview of all Spinal Cord Injury (SCI) recommendations; and has been used quite extensively in SCI [18]. Gustafsson et al. in 2013 analyzed the clinical utility of the COPM for an SCI population, through a focus group composed of six occupational therapists; however, the clinimetric properties of this tool have never been studied for SCI populations. Usually, for construct validity, all the dimensions of the COPM have been compared with traditional, non- individualized questionnaires constructed to measure the functioning of the specific population in which the construct should theoretically relate with that of COPM [19-28]. Despite difficulties in studying validity in individualized tools such as the COPM [35], no other method yet exists to determine its validity besides testing its correlation with more traditional measures of functioning and quality of life. Clinically, the score that is the most significant in this tool is the change score, which evaluates changes between the client's satisfaction scores or performance scores in the activities identified by him at the initial assessment and reevaluation of the same activities [19-31]. This means that responsiveness to change over time is a crucial and needed factor of the validation process, although it has often remained unstudied.

The main purpose of the study is to analyze the construct validity, test-retest reliability, and the ability to detect change of the Italian version of the COPM [24] in a sample of SCI clients by comparing its results with the results of a diagnosis-specific measure of functioning: the Italian version of the Spinal Cord Independence Measure Version III (SCIM III) [36, 37]. The SCIM III is a fixed-item questionnaire constructed to measure physical functioning.

\section{Methods}

\section{Participants and procedures}

Participants were recruited from an Italian rehabilitation service for SCI patients in a spinal unit. The individuals from the chronic SCI population were enrolled in a rehabilitation program after having from pressure injuries. The Occupational Therapy program was part of usual care for these patients. The intervention of occupational therapist (OT) started 30 days after the surgery for pressure injuries with short-sitting in the edge of the bed to monitor skin and sitting tolerance [38]. OTs, like their colleagues in other disciplines, adhered to pressure relief programs and were involved in procurement of appropriate equipment and in activities and specific therapy interventions included in the skin management. The goals of the OT included: procurement of new equipment to address seating needs (pressure mapping, cushion and backrest evaluation, and trials); patient education regarding skin inspection and transfers safety; and the prevention of a new pressure injury. The OT has the responsibility to ensure that treatments match needs are safe and evidence-based. The COPM is often used to determine the priority of each individual when prescribing new equipment and to detect any eventual problem among the activities of daily living to work on. All the participants were also attending physiotherapist's and nursing therapies.

To qualify for participation in the study, interested participants had to be adults ( $>18$ years old) with chronic SCI 
( $>1$ year since injury). All eligible individuals were informed of the study procedures and scope; those who were interested in taking part in the research gave their explicit consent before being included [39]. The participants included in the study were scheduled for three testing sessions $(\mathrm{T} 1, \mathrm{~T} 2, \mathrm{~T} 3)$. All participants were tested twice in the first week (T1,T2 - within 6 days) for test-retest reliability and once in the last week of the rehabilitation program (T3 —within 12 weeks) — by the same occupational therapistto assess the ability to detect change. The problems were identified in the first administration and in the following testing sections the participants were asked to rate again their performance and satisfaction in the same activities. The therapist who administered the Italian translated and culturally adapted version of the COPM [24] was not the same as the one who treated the individual; this choice was made to limit the "hello-goodbye effect," [40] a phenomenon where clients undervalue their skills at the first administration to get help and after the treatment overvalue their skills. This often happens when individuals are interviewed after treatment by their own therapists [41]. The program, composed of six hours of occupational therapy each week, aimed to improve participants' daily living independence through activities, training, and aids for everyday life based on the personal activities identified by clients as occupational performance problems during the administration of the COPM.

\section{Instruments}

The COPM and the SCIM III were administered together, the first was administered by interview, whereas the SCIM III was self-reported. The COPM [23] is an individualized, client-centered outcome measure. In a semi-structured interview, the individuals, identify upto five occupational activities considered by them as a problem for themselves. This step is the basis for identifying treatment goals. The individuals are then asked to use a 10-point scale in order to assess their current performance and satisfaction with each of the selected issues. The therapist evaluates COPM performance and satisfaction score dividing the sum of the assigned score by the number of problems identified [42]. After the treatment, the individuals are asked again to selfrate their level of performance and satisfaction for the same problems. These scores are used by the therapist to calculate the change scores.

The SCIM III-self report is a tool that assesses the independence of individuals with SCIs. It is comprised of 19 items of daily living activities that are categorized into three subscales that evaluate self-care, respiration and sphincter management, and mobility. The total SCIM III score ranges from 0 to 100 , with higher scores reflecting better performance or greater independence.
Reliability, validity, and the ability to detect change

The clinimetric properties of the COPM were evaluated in a SCI sample in accordance to the "consensus-based standards for the selection of health status measurement instruments" (COSMIN) checklist [43]. All the statistical analyses were carried out with the Statistical Package for the Social Sciences (SPSS) version 18.0. Following the COSMIN checklist, the clinimetric properties of the COPM were assessed through Cronbach's alpha for internal consistency and the intraclass correlation coefficient (ICC) for test-retest reliability. Internal consistency and test-retest reliability were calculated on the performance average score and satisfaction average score and a minimum value of 0.70 was considered minimum acceptable for both coefficients. For construct validity, the correlation between the COPM and the SCIM III was evaluated using Pearson's correlation coefficient and Spearman's Rho [44, 45]. The strength of association was interpreted according to Portney and Watkins: $0.0-0.25$ little or no relationship; $0.25-0.50$ fair association/relationship; 0.50-0.75 moderate to good association; above 0.75 good to excellent relationship [46, 47]. Values greater than 0.5 or less than -0.5 were considered acceptable, to believe that there is support for COPM construct validity, where a positive value meant positive correlation and a negative value meant negative correlation between tools. In analyzing the correlation between the two tools, we expected to find weak correlations between the COPM and the SCIM III because of the structure of the questionnaires, which clearly differed from each other. The COPM was administered a second time after the rehabilitation program, and the first scores were subtracted from the seconds to obtain the change scores following the instruction of the Canadian developers [42]. The participants knew the purpose of the study; however, they were blind or naïve about their scores at admission. Regarding interpretability, that is the degree to which one can assign qualitative meaning to an instrument's quantitative scores or change in scores, as stated in the COPM manual, a change of two or more points on the performance, satisfaction is considered clinically significant [42]. Moreover, one study has found the cutoff to be 1.37 points and 1.90 points for occupational performance and satisfaction with occupational performance, respectively [44]. However, the Dutch authors used a transition measure, and the change score was the average COPM change score for patients who after their treatment sequence was completed stated that they had improved. The ability to detect change was measured by evaluating changes on the COPM from the start of rehabilitation program (T0) to the end of the treatment period of 12 weeks (T2). To assess the ability to detect change between $\mathrm{T} 0$ and $\mathrm{T} 2$ for the COPM, a Wilcoxon signed-rank test was used. The significance level has been set for $p$-value less than or equal to 0.05 [44]. 


\section{Results}

\section{Population and procedures}

Thirty nine adults with chronic SCI were recruited from the rehabilitation service of the paraplegic center in Ostia, Rome. All of the 39 eligible participants agreed to participate and were included in the study. The demographic characteristics of the participants are reported in Table 1 . The population was evaluated with the COPM and the SCIM III. Table 2 represents frequencies and percentages of the occupation, resulted from the COPM administration, summarized in area of interest. Area 1 represent the first occupational problem mentioned, area 2 the second, and so on. '" represents "I don't have a second/third/fourth/fifth problem". The problems resulted from the administration were: Self-care (e.g., bathroom management), functional mobility with wheelchair (e.g., outdoor mobility), socialization, leisure (e.g., outdoor activities), household management, productivity (e.g., sitting tolerance at work). These problems have been addressed by the OT through analysis and training on the activities of daily living; assessment of bathroom equipment for example proposing new technologies, such as the Transanal irrigation (TAI) a safe bowel management therapy; and procurement of new equipment to address seating needs.

Table 1 Demographic characteristics for the 39 participants in the reliability study of the COPM

\begin{tabular}{ll}
\hline Age $($ mean \pm SD) & $53 \pm 15$ \\
Gender men $(\%)$ & 71 \\
Years from Injury (mean \pm SD) & $15 \pm 14$ \\
Neurological Level of injury & Number $(\%)$ \\
C4 & $1(2.5)$ \\
C5 & $8(20.5)$ \\
C6 & $5(13)$ \\
C7 & $2(5)$ \\
C8 & $1(2.5)$ \\
D1 & $1(2.5)$ \\
D3 & $1(2.5)$ \\
D4 & $1(2.5)$ \\
D5 & $3(8)$ \\
D6 & $4(10)$ \\
D7 & $2(5)$ \\
D8 & $2(5)$ \\
D9 & $1(2.5)$ \\
D10 & $1(2.5)$ \\
D12 & $3(8)$ \\
L1 & $2(5)$ \\
L3 & $1(2.5)$ \\
\hline
\end{tabular}

Reliability, validity, and the ability to detect change

The COPM had a high degree of internal consistency with a Cronbach's alpha value of 0.93 for performance score and 0.89 for satisfaction score (T0). In addition, the tool had a high ICC value, which indicates great test-retest reliability, after repeated measurements with a value of 0.99 for the performance and 0.98 for the satisfaction. The reliability values are reported in Table 3 . Furthermore, the COPM's construct validity with the SCIM III did not demonstrate a statistically significant correlation $(p<$ 0.05), neither with the Pearson's correlation coefficient nor with the Spearman's Rho coefficient, as shown in

Table 2 Frequencies and percentages of the meaningful occupation resulted from the COPM synthetized in area of interest

\begin{tabular}{|c|c|c|}
\hline & Frequency & Percentage \\
\hline \multicolumn{3}{|l|}{ Area 1} \\
\hline Self-care & 19 & 49 \\
\hline Functional mobility with wheelchair & 14 & 36 \\
\hline Leisure & 4 & 10 \\
\hline Household management & 2 & 5 \\
\hline \multicolumn{3}{|l|}{ Area 2} \\
\hline Functional mobility with wheelchair & 14 & 36 \\
\hline Self-care & 11 & 28 \\
\hline / & 8 & 20 \\
\hline Household management & 4 & 10 \\
\hline Productivity & 1 & 3 \\
\hline Leisure & 1 & 3 \\
\hline \multicolumn{3}{|l|}{ Area 3} \\
\hline / & 17 & 44 \\
\hline Leisure & 8 & 20 \\
\hline Functional mobility with wheelchair & 6 & 15 \\
\hline Household management & 5 & 13 \\
\hline Self-care & 3 & 8 \\
\hline \multicolumn{3}{|l|}{ Area 4} \\
\hline / & 28 & 71 \\
\hline Self-care & 3 & 8 \\
\hline Functional mobility with wheelchair & 3 & 8 \\
\hline Leisure & 2 & 5 \\
\hline Household management & 1 & 3 \\
\hline Productivity & 1 & 3 \\
\hline Socialization & 1 & 3 \\
\hline \multicolumn{3}{|l|}{ Area 5} \\
\hline / & 35 & 90 \\
\hline Household management & 2 & 5 \\
\hline Functional mobility with wheelchair & 1 & 3 \\
\hline Socialization & 1 & 3 \\
\hline
\end{tabular}

Note: Area 1 represents the first occupational problem mentioned, area 2 the second, and so on. '/' represents "I don't have a second/ third/ fourth/ fifth problem" 
Table 3 Test-retest analysis: Range of ICC parameters of each item the Italian version of the COPM

Table 4 Construct validity analysis: Spearman's Rho correlation and Pearson's correlation coefficient between COPM and the Italian version of the SCIM III

\begin{tabular}{llllll}
\hline & Mean test $(\mathrm{SD})$ & Mean $(\mathrm{SD})$ retest & ICC & CI [95\%] & $p$ \\
\hline COPM performance & $4.5(2.2)$ & $4.6(2.2)$ & 0.99 & $0.992-0.996$ & $<0.01$ \\
COPM satisfaction & $4.6(2.5)$ & $4.7(2.4)$ & 0.89 & $0.98-0.94$ & $<0.01$ \\
\hline
\end{tabular}

\begin{tabular}{llll}
\hline Spearman's Rho & SCIM & Mean performance T0 & Mean satisfaction T0 \\
\hline SCIM & 1 & 0.30 & 0.17 \\
Mean performance T0 & 0.30 & 1 & $0.80^{\mathrm{a}}$ \\
Mean satisfaction T0 & 0.17 & $0.80^{\mathrm{a}}$ & 1 \\
\hline Pearson's correlation coefficient & SCIM & Mean performance T0 & Mean satisfaction T0 \\
\hline SCIM & 1 & 0.30 & 0.22 \\
Mean performance T0 & 0.30 & 1 & $0.80^{\mathrm{a}}$ \\
Mean satisfaction T0 & 0.22 & $0.80^{\mathrm{a}}$ & 1 \\
\hline
\end{tabular}

${ }^{\mathrm{a}}$ Correlation is significant at the 0.01 level (2-tailed)

Table 5 Pearson's correlation coefficient between COPM (first occupational problem mentioned by participants) and the SCIM III

\begin{tabular}{|c|c|c|c|c|}
\hline $\begin{array}{l}\text { Area 1-the first occupational problem mentioned } \\
\text { for COPM }\end{array}$ & $\begin{array}{l}\text { Self-care } \\
\text { subscale }\end{array}$ & $\begin{array}{l}\text { Respiration and sphincter management } \\
\text { subscale }\end{array}$ & $\begin{array}{l}\text { Mobility } \\
\text { subscale }\end{array}$ & $\begin{array}{l}\text { SCIM } \\
\text { III Total }\end{array}$ \\
\hline Self care-mean performance. T0 & $-0.63^{\mathrm{a}}$ & $-0.74^{\mathrm{a}}$ & $-0.60^{\mathrm{a}}$ & $-0.73^{\mathrm{a}}$ \\
\hline Self care-mean satisfaction. T0 & $-0.571^{\mathrm{b}}$ & $-0.66^{\mathrm{a}}$ & $-0.51^{\mathrm{b}}$ & $-0.66^{\mathrm{a}}$ \\
\hline Household management -mean performance. T0 & $0.99^{\mathrm{a}}$ & $0.99^{\mathrm{a}}$ & $0.99^{\mathrm{a}}$ & $0.99^{\mathrm{a}}$ \\
\hline Household management- mean satisfaction. T0 & $0.97^{\mathrm{a}}$ & $0.97^{\mathrm{a}}$ & $0.91^{\mathrm{a}}$ & $0.96^{\mathrm{a}}$ \\
\hline $\begin{array}{l}\text { Functional mobility with wheelchair -mean } \\
\text { performance. T0 }\end{array}$ & $0.54^{\mathrm{b}}$ & $0.49^{\mathrm{b}}$ & $0.60^{\mathrm{a}}$ & $0.56^{\mathrm{b}}$ \\
\hline $\begin{array}{l}\text { Functional mobility with wheelchair -mean } \\
\text { satisfaction. T0 }\end{array}$ & $0.63^{\mathrm{a}}$ & $0.51^{\mathrm{b}}$ & $0.64^{\mathrm{a}}$ & $0.62^{\mathrm{a}}$ \\
\hline Leisure-mean performance. T0 & $0.77^{\mathrm{a}}$ & $0.84^{\mathrm{a}}$ & $0.73^{\mathrm{a}}$ & $0.93^{\mathrm{a}}$ \\
\hline Leisure-mean satisfaction. T0 & $0.80^{\mathrm{a}}$ & $0.85^{\mathrm{a}}$ & $0.77^{\mathrm{a}}$ & $0.91^{\mathrm{a}}$ \\
\hline
\end{tabular}

${ }^{a}$ Correlation is significant at the 0.01 level (2-tailed)

${ }^{\mathrm{b}}$ Correlation is significant at the 0.05 level (2-tailed)

Table 4. However, Pearson's correlation coefficient performed between the first occupational problem mentioned by participants and SCIM III showed moderate to excellent relationship as shown in Table 5. For the ability to detect change of the measure, the null hypothesis that no clinical change would occur between $\mathrm{T} 0$ and $\mathrm{T} 2$ was rejected, as shown in Table 6. In fact, the mean change between $\mathrm{T} 0$ and $\mathrm{T} 2$ as evaluated with a Wilcoxon signedrank test was -4.25 for the performance score and -2.96 for the satisfaction score, respectively. Therefore, the improvement on the COPM scores during the treatment period were not only clinically significant ( $>-2.0$ points), as suggested by the Canadian developers of the tool [43], but also statistically significant $(p<0.01)$.

\section{Discussion}

Consistent with the structure of the COPM [43], the change score is the most relevant. It measures change between the scores at an initial evaluation and at reevaluation; this means that although not commonly studied, the assessment of the responsiveness to change over time is a crucial and needed factor for the validation process. In the last few years, the COPM has been used as an outcome measure in several studies of spinal cord injury rehabilitation [13-17]. However, its clinimetric properties, particularly the ability to detect change, have never been analyzed for this population prior to this study. Therefore, this research focused on the ability to detect change of the measure and the construct 
Table 6 Ability to detect change: responsiveness of the COPM Wilcoxon signed-rank test on 39 participants

\begin{tabular}{lllll}
\hline & T0 mean \pm SD & T1 mean \pm SD & Mean difference \pm SD [CI 95\%] & $p$ \\
\hline COPM performance & $4.55 \pm 2.21$ & $6.20 \pm 2.12$ & $-4.25^{\mathrm{a}}$ & $0.001^{\mathrm{b}}$ \\
COPM satisfaction & $4.62 \pm 2.49$ & $6.54 \pm 2.27$ & $-2.96^{\mathrm{a}}$ & $0.003^{\mathrm{b}}$ \\
\hline
\end{tabular}

${ }^{a}$ Based on negative ranks

${ }^{\mathrm{b}}$ Correlation is significant at the 00.01 level

validity of the COPM in a sample of persons with SCI. The 39 respondents were evaluated at $\mathrm{T} 0$ with the COPM and the SCIM III, and at T2, after a 3-month rehabilitation program based on the daily activities that were reported during the administration of the COPM. During the administration of the COPM, the first activities that the participants wanted or needed to work with to improve their satisfaction were related mainly to personal care (39\%) and functional mobility (20\%). The rehabilitation program was specific to each individual and based on the activity he or she identified. For example, for personal care, treatments were oriented to training on assistive technologies identified by the therapist, and for functional mobility, treatments were oriented to wheelchair configuration and postural alignment.

The clinimetric properties of the COPM in a sample of SCI clients demonstrated positive values for internal consistency, test-retest reliability, and the ability to detect change (Table 3-5), proving that the COPM is a suitable and reliable tool for assessing the achievement of results in terms of satisfaction and the perception of improvement in performance. The construct validity results showed that the SCIM III was not linked to the COPM total score, which is expressed by the mean scores for performance and satisfaction of all occupational problems identified by clients. In discovering this correlation, the results of this study coincide with previous ones $[9,29,33,40,48-51]$. However, not all participants expressed the same number of problems, performing the Pearson's correlation coefficient between the first occupational problem mentioned as by participants and SCIM III subscale resulted in moderate to excellent relationship. The study's results suggest that one explanation for the lack of correlation between the COPM and other existing measures is the strong value of client-specific items in rehabilitation intervention planning and monitoring at an individual level [33].

\section{Limits of the study}

This study has some limitations. The sample size was too small to allow comparisons among the problem category distribution of those interviewed. For example, correlations with the neurological level of lesions, years since injury, and so on. Furthermore, future research should first determine the most common priorities of the studied population and then select the comparison tool for construct validity or the ability to detect change testing of the COPM [33].

\section{Conclusions}

Based on the results of this study, it can be concluded that the COPM is a suitable tool for SCI populations when used to determine treatment goals and measure the perception of improvement in everyday-life independence in SCI clients. This work represents a starting point for the in-depth study of SCI patients' perception of their disability and represents an important step for clinical and research practice, especially for qualitative studies.

\section{Data availability}

The datasets generated and/or analyzed during the current study are available from the corresponding author on reasonable request.Data availabilityThe datasets generated and/ or analyzed during the current study are available from the corresponding author on reasonable request.

\section{Compliance with ethical standards}

Conflict of interest The authors declare that they have no conflict of interest.

Ethical approval We certify that all applicable institutional and governmental regulations concerning the ethical use of human volunteers were followed during the course of this research. All procedures followed were in accordance with the ethical standards of the responsible committee on human experimentation (institutional and national) and with the Helsinki Declaration of 1975, as revised in 2008.

Informed consent Informed consent was obtained from all participants for being included in the study.

Publisher's note: Springer Nature remains neutral with regard to jurisdictional claims in published maps and institutional affiliations.

\section{References}

1. Singh A, Tetreault L, Kalsi-Ryan S, Nouri A, Fehlings MG. Global prevalence and incidence of traumatic spinal cord injury. Clin Epidemiol. 2014;6:309-31.

2. Schipper H, Clinch JJ, Olweny CL. Quality of life studies: definitions and conceptual issues. In: Spilker B (ed.) Quality of life 
and pharmacoeconomics in clinical trials. Philadelphia: Lippincott-Raven; 1996. p. 11-23.

3. Healthypeople.gov. Office of Disease Prevention and Health Promotion. Available from: https://www.healthypeople.gov/sites/ default/files/HRQoLWBFullReport.pdft. Accessed 15 Dec 2019.

4. Ware JE Jr, Sherbourne CD. The MOS 36-Item Short-Form Health Survey (SF-36). I. Conceptual framework and item selection. Med Care. 1992;30:473-83.

5. Chen TH, Li L, Kochen MM. A systematic review: How to choose appropriate health-related quality of life (HRQOL) measures in routine general practice? J Zhejiang Univ Sci B. 2005;6:936-40.

6. Ware JE Jr. The status of health assessment 1994. Annu Rev Public Health. 1995;16:327-54.

7. Haley SM, Coster WJ, Binda-Sundberg K. Measuring physical disablement: the contextual challenge. Phys Ther. 1994;74: 443-51.

8. Townsend E. Enabling occupation: an occupational therapy perspective. Ottawa: Canadian Association of Occupational Therapists; 1997.

9. Cup EH, Scholte op Reimer WJ, Thijssen MC, van KuykMinis MA. Reliability and validity of the Canadian Occupational Performance Measure in stroke patients. Clin Rehabil. 2003; 17:402-9.

10. Clark NM, Janz NK, Dodge JA, Mosca L, Lin X, Long Q, et al. The effect of patient choice of intervention on health outcomes. Conte Clin Trials. 2008;29:679-86.

11. Heyn L, Finset A, Eide H, Ruland CM. Effects of an interactive tailored patient assessment on patient-clinician communication in cancer care. Psychooncology. 2013;22:89-96.

12. Law M, Baptiste S, Carswell A, McColl MA, Polatajko H, Pollock N. Canadian Occupational Performance Measure. Toronto: Canadian Association of Occupational Therapists; 2005.

13. Chompoonimit A, Nualnetr N. The impact of task-oriented clientcentered training on individuals with spinal cord injury in the community. Spinal Cord. 2016;54:849-54.

14. Johanson ME, Jaramillo JP, Dairaghi CA, Murray WM, Hentz VR. Multicenter survey of the effects of rehabilitation practices on pinch force strength after tendon transfer to restore pinch in tetraplegia. Arch Phys Med Rehabil. 2016;97:105-16.

15. Vincent C, Gagnon DH, Dumont F. Pain, fatigue, function and participation among long-term manual wheelchair users partnered with a mobility service dog. Disabil Rehabil Assist Technol. 2019;14:99-108.

16. Burns AS, Marino RJ, Kalsi-Ryan S, Middleton JW, Tetreault LA, Dettori JR, et al. Type and timing of rehabilitation following acute and subacute spinal cord injury: a systematic review. Glob Spine J. 2017;7:175S-194S.

17. Wangdell J, Reinholdt C, Fridén J. Activity gains after upper limb surgery for spasticity in patients with spinal cord injury. J Hand Surg Eur. 2018;43:613-20.

18. Mulcahey MJ, Vogel LC, Sheikh M, Arango-Lasprilla JC, Augutis M, Garner E, et al. Recommendations for the National Institute for Neurologic Disorders and Stroke spinal cord injury common data elements for children and youth with SCI. Spinal Cord. 2017;55:331-40.

19. Spadaro A, Lubrano E, Massimiani MP, Gaia P, Perrotta FM, Parsons WJ, et al. Validity, responsiveness and feasibility of an Italian version of the Canadian Occupational Performance Measure for patients with ankylosing spondylitis. Clin Exp Rheuma. 2010;28:215-22.

20. Thyer L, Brown T, Roe D. The Validity of the Canadian Occupational Performance Measure (COPM) When Used in a SubAcute Rehabilitation Setting with Older Adults. Occup Ther Health Care. 2018;32:137-53.
21. Donnelly C, O’Neill C, Bauer M, Letts L. Canadian Occupational Performance Measure (COPM) in primary care: a profile of practice. Am J Occup Ther. 2017;71:1-8.

22. Yang SY, Lin CY, Lee YC, Chang JH. The Canadian occupational performance measure for patients with stroke: a systematic review. J Phys Ther Sci. 2017;29:548-55.

23. Tuntland H, Aaslund MK, Langeland E, Espehaug B, Kjeken I. Psychometric properties of the Canadian Occupational Performance Measure in home-dwelling older adults. J Multidiscip Health. 2016;9:411-23.

24. Švajger A, Piškur B. The clinical utility of the Canadian Occupational Performance Measure in vocational rehabilitation: a qualitative study among occupational therapists in Slovenia. Work. 2016;54:223-33.

25. Marinho FS, Moram CB, Rodrigues PC, Franzoi AC, Salles GF, Cardoso CR. Profile of disabilities and their associated factors in patients with type 2 diabetes evaluated by the Canadian occupational performance measure: the Rio De Janeiro type 2 diabetes cohort study. Disabil Rehabil. 2016;38:2095-101.

26. van de Ven-Stevens LA, Graff MJ, Peters MA, van der Linde H, Geurts AC. Construct validity of the Canadian Occupational Performance Measure in participants with tendon injury and Dupuytren disease. Phys Ther. 2015;95:750-7.

27. Padankatti SM, Macaden AS, Cherian SM, Thirumugam M, Pazani D, Kalaiselvan $\mathrm{M}$, et al. A patient-prioritized ability assessment in haemophilia: the Canadian Occupational Performance Measure. Haemophilia. 2011;17:605-11.

28. Gustafsson L, Mitchell G, Fleming J, Price G. Clinical utility of the Canadian Occupational Performance Measure in spinal cord injury rehabilitation. Br J Occup Ther. 2012;75:337-42. https:// doi.org/10.4276/030802212X13418284515910.

29. Kjeken I, Slatkowsky-Christensen B, Kvien TK, Uhlig T. Norwegian version of the Canadian Occupational Performance Measure in patients with hand osteoarthritis: validity, responsiveness, and feasibility. Arthritis Rheum. 2004;51:709-15.

30. Persson E, Rivano-Fischer M, Eklund M. Evaluation of changes in occupational performance among patients in a pain management program. J Rehabil Med. 2004;36:85-91.

31. Wressle E, Lindstrand J, Neher M, Marcusson J, Henriksson C. The Canadian Occupational Performance Measure as an outcome measure and team tool in a day treatment programme. Disabil Rehabil. 2003;25:497-506.

32. Colquhoun H, Letts L, Law M, MacDermid J, Edwards M. Feasibility of the Canadian Occupational Performance Measure for routine use. Br J Occup Ther. 2010;73:48-54.

33. Nieuwenhuizen MG, de Groot S, Janssen TWJ, van der Maas LCC, Beckerman H. Canadian Occupational Performance Measure performance scale: validity and responsiveness in chronic pain. JRRD. 2014;51:727-46.

34. Eyssen IC, Steultjens MP, Oud TA, Bolt EM, Maasdam A, Dekker J. Responsiveness of the Canadian Occupational Performance Measure. J Rehabil Res Dev. 2011;48:517.

35. Jolles BM, Buchbinder R, Beaton DE. A study compared nine patient-specific indices for musculoskeletal disorders. J Clin Epidemiol. 2005;58:791-801.

36. Bonavita J, Torre M, China S, Bressi F, Bonatti E, Capirossi R, et al. Validation of the Italian version of the Spinal Cord Independence Measure (SCIM III) Self-Report. Spinal Cord. 2016;54:553-60.

37. Catz A, Itzkovich M, Agranov E, Ring H, Tamir A. SCIM-spinal cord independence measure: a new disability scale for patients with spinal cord lesions. Spinal Cord. 1997;35:850-6.

38. Ozelie R, Sipple C, Foy T, Cantoni K, Kellogg K, Lookingbill J, et al. SCI Rehab Project Series: the occupational therapy taxonomy. J Spinal Cord Med. 2009;32:283-96. 
39. Galeoto G, De Santis R, Marcolini A, Cinelli A, Cecchi R. Il consenso informato in Terapia Ocupazionale: proposta di una modulistica. G Ital Med Lav Erg. 2016;38:107-15.

40. Portney LG, Watkins MP. Foundations of clinical research: applications to practice. 3rd edn. Upper Saddle River, New Jersey, USA: Pearson; 2008.

41. Streiner DL, Norman GR. Health measurement scales: a practical guide to their development and use. 3rd edn. Oxford: Oxford University Press; 2003.

42. COPM. The Canadian Occupational Performance Measure. www. copm.ca. Accessed 15 Dec 2019.

43. Eyssen IC, Steultjens MP, Oud TA, Bolt EM, Maasdam A, Dekker J. Responsiveness of the Canadian Occupational Performance Measure. J Rehabil Res Dev. 2011;48:517-28.

44. Tuntland H, Aaslund MK, Langeland E, Espehaug B, Kjeken I. Psychometric properties of the Canadian Occupational Performance Measure in home-dwelling older adults. J Multidiscip Healthc. 2016;9:411-23.

45. Carpenter L, Baker GA, Tyldesley B. The use of the Canadian Occupational Performance Measure as an outcome of a pain management program. Can J Occup Ther. 2001;68:16-22.
46. Mokkink LB, Terwee CB, Patrick DL, Alonso J, Stratford PW, Knol DL, et al. The COSMIN checklist for assessing the methodological quality of studies on measurement properties of health status measurement instruments: an international Delphi study. Qual Life Res. 2010;19:539-49.

47. Chan CC, Lee TM. Validity of the Canadian Occupational Performance Measure. Occup Ther Int. 1997;4:231-49.

48. Dedding C, Cardol M, Eyssen IC, Dekker J, Beelen A. Validity of the Canadian Occupational Performance Measure: A clientcentred outcome measurement. Clin Rehabil. 2004;18:660-67.

49. Ripat J, Etcheverry E, Cooper J, Tate RB. A comparison of the Canadian Occupational Performance Measure and the Health Assessment Questionnaire. Can J Occup Ther. 2001; 68:247-53.

50. Verkerk GJ, Wolf MJ, Louwers AM, Meester-Delver A, Nollet F. The reproducibility and validity of the Canadian Occupational Performance Measure in parents of children with disabilities. Clin Rehabil. 2006;20:980-88.

51. de Vet HC, Terwee CB, Mokkink LB, Knol DL. Measurement in medicine: a practical guide. Cambridge: Cambridge University Press; 2011. 